
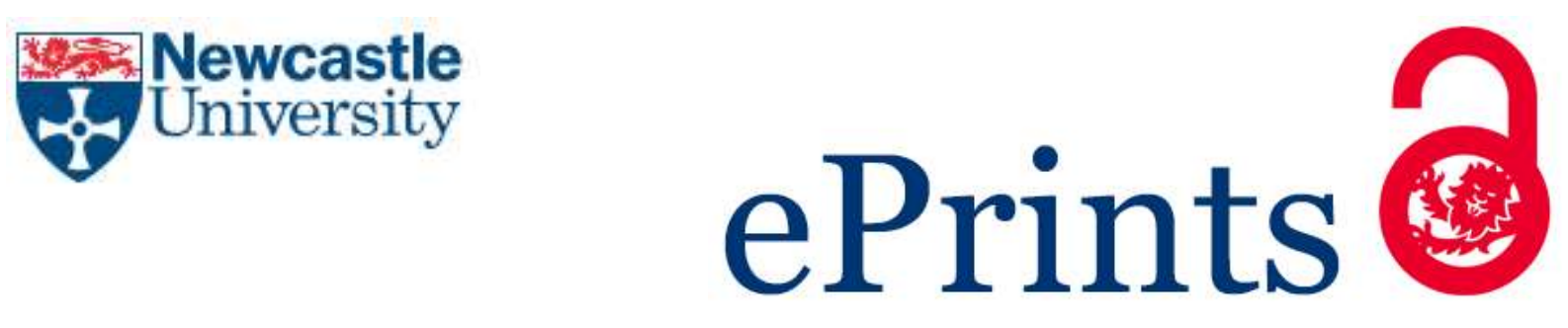

Lisle TJ, Shaw BA, Frazer RC. Internal spur gear root bending stress: A comparison of ISO 6336:1996, ISO 6336:2006, VDI 2737:2005, AGMA, ANSYS

finite element analysis and strain gauge techniques. Proceedings of the Institution of Mechanical Engineers Part C: Journal of Mechanical Engineering Science 2018

\title{
Copyright:
}

This is the authors' accepted manuscript of an article that has been published in its final definitive form by SAGE Publications, 2018

DOI link to article:

https://doi.org/10.1177/0954406218774364

Date deposited:

$22 / 05 / 2018$ 


\title{
Corresponding author:
}

Lisle TJ, Design Unit, Newcastle University, Newcastle upon Tyne. NE1 7RU, UK

Email: Timothy.lisle@ncl.ac.uk

\section{Internal spur gear root bending stress: A comparison of ISO 6336:1996, ISO 6336:2006, VDI 2737:2005, AGMA, ANSYS finite element analysis and strain gauge techniques}

\author{
TJ Lisle ${ }^{1}$, BA Shaw ${ }^{1}$ and RC Frazer ${ }^{1}$ \\ ${ }^{1}$ Design Unit, Newcastle University, UK
}

\begin{abstract}
The Association of German Engineers VDI 2737:2005 and the International Organisation for Standardisation ISO 6336:2006 are universally accepted analytical procedures for the analysis of internal gears. There is no official American Gear Manufacturers Association (AGMA) standard for internal gear stress analysis due to the validity of inscribing the Lewis parabola within internal concave profiles and the resulting errors associated with the location of maximum root bending stress. This research investigates the differences associated with using ISO 6336, VDI 2737 and an unofficial AGMA method, all of which are compared against a potentially more accurate numerical (ANSYS) method and strain gauge techniques.
\end{abstract}

\section{Keywords}

Internal gear; root bending stress; ANSYS finite element analysis; strain gauges; ISO 6336:2006; VDI2737:2005

\section{Introduction}

Since 1893, when Lewis ${ }^{1}$ proposed that the stresses in gear tooth roots could be established by approximating their analysis as simple beams in bending, the complexity of gear stress analysis has progressed considerably into its current guise, more of which will be discussed later. Significant advances in gear research coincided with the advent of what were novel stress analysis techniques such as photoelasticity ${ }^{2-7}$ and numerical finite element methods ${ }^{8-17}$ which became common place in the early and late 1900's respectively, a summary of which has already been discussed in detail by Lisle et al. ${ }^{18}$ Arguably, the historic majority of this research concentrated on the analysis of external gears, as opposed to internal gears, the stress analysis of which is now of equal importance, especially with regards to the aerospace industry.

In 1996, the International Organisation for Standardisation released the first version of ISO $6336^{19}$ responsible for internal (and external) gear stress analysis, assuming that the location of maximum internal tooth root bending stress coincided with that of external gears, i.e. the 30 degree tangent point, as illustrated in Figure 1. After its revision in $2006^{20}$, this dramatically changed to 60 degrees raising concerns 
over designs prior to 2006. The Association of German Engineers released VDI 2737:2005 ${ }^{21}$ which only analyses internal gears but augments ISO 6336:2006 by accounting for rim deflections, radial tooth loads and centrifugal forces. The American Gear Manufacturers Association do not have an official method for internal gear stress analysis due to the method by which it determines the critical section. I.e. the location of maximum root bending stress based on the inscribed Lewis parabola ${ }^{1}$ which as stated by AGMA 908-B8922 is "inaccurate for short, stubby beams". However, the AGMA method has been independently adapted by Savage et al. ${ }^{23}$ based on the work of Lewis ${ }^{1}$ and Dolan and Broghamer ${ }^{3}$ albeit with uncertain results; this will be investigated and designated the internal AGMA method, but it must be re-iterated that this is not an official AGMA method: It is merely included here to highlight its pitfalls.

All methods of gear stress analysis produce different results, often for a number of reasons, however this research aims to compare only the nominal stresses (those without any load or stress increasing factors) calculated in accordance with ISO 6336:2006, ISO 6336:1996, VDI 2737:2005 and the AGMA method. Furthermore, although VDI 2737:2005 has the ability to accommodate thin rim deflections, the work herein is based on thick, un-deformable rims and as such that part of the VDI method is not investigated; this does not detract from the quality and ability of the standard to deal with thin rim deflections. Based on the success of the external root bending stress validation ${ }^{18}$ the results will also be compared with numerical finite element analysis (ANSYS) and experimental strain gauge techniques.

For reference, 1) ISO 6336:1996, ISO 6336:2006 and VDI 2737:2005 will be designated as ISO 1996, ISO 2006 and VDI respectively, 2) ANSYS 12.1 was the chosen FEA package, and 3) Dontyne Systems Gear Production Suite generated the accurate 2D internal tooth profiles based on shaper cutter generation.

\section{ISO, VDI and AGMA root bending stress}

Internal root bending stresses established in accordance with ISO, VDI (step 1, neglecting centrifugal forces) and the internal AGMA method, are established as follows,

$$
\begin{gathered}
\sigma_{F(I S O)}=\frac{F_{t}}{b \cdot m_{n}} \cdot Y_{F} \cdot Y_{S} \\
\sigma_{F(V D I)}=\frac{F_{t} \cdot}{b \cdot m_{n}} \cdot Y_{F S} \\
\sigma_{F(A G M A)}=\frac{F_{t}}{b} \cdot \frac{K_{f}}{Y}
\end{gathered}
$$

Equations (1) through to (3) are analogous to those used for external gears, where $F_{t}, b$ and $m_{n}$ are the tangential force, facewidth and normal module respectively. The height and second moment of area of the tooth are accounted for via the form $\mathrm{Y}_{\mathrm{F}}$ (ISO) and geometry Y (AGMA) factors, whilst the root fillet radius is used to determine the stress concentration factors $\mathrm{Y}_{\mathrm{S}}$ (ISO) and $\mathrm{K}_{\mathrm{f}}$ (AGMA). VDI differs slightly in its appearance since it combines the stress concentration factor $Y_{S a b}$ together with the form factor for bending $\mathrm{Y}_{\mathrm{Fa}}$ and compression $\mathrm{Y}_{\mathrm{Fad}}$ to produce the tip factor $\mathrm{Y}_{\mathrm{FS}}$. Indeed, the foundation 
for all three of these stress analysis methods are identical, nevertheless discrepancies arise due to a number of significant factors, namely,

- The original release of ISO 1996 based the critical section on the $30^{\circ}$ tangent point, as per its external gear stress analysis procedures. ISO 2006 and VDI both use the $60^{\circ}$ tangent point whilst the AGMA method adopts the inscribed Lewis parabola, for which Savage et al. ${ }^{23}$ present a method for its determination, analogous to that provided by Dolan and Broghamer ${ }^{3}$ for external gears. Figure 1 provides a summary of the different methods.

- Both VDI and AGMA resolve and superpose the normal tooth force $\left(\mathrm{F}_{\mathrm{bt}}\right)$ into its tangential $\left(\mathrm{F}_{\mathrm{t}}\right)$ and radial $\left(\mathrm{F}_{\mathrm{r}}\right)$ components, each of which creates a tensile and compressive stress - in the tensile root - respectively.

- Both ISO 1996 and ISO 2006 do not account for the radial component of tooth loading.

- Both ISO 6336:2006 and VDI 2737:2005 establish iteratively the root fillet radius at the 60 degree tangent point based on the tool tip radius, albeit they can produce different results.

- Since there is no official AGMA standard for internal gears, there is no method for establishing the AGMA root fillet radius required for the stress concentration factor. For the purpose of this research, it was decided to establish the root fillet radius in accordance with VDI, for use with AGMA.

- ISO 1996 does not account for the true geometrical tooth shape. Instead it is replaced with an equivalent straight sided "special rack". The reader is directed to ISO6336: $1996^{19}$ for further information.

- ISO 2006, VDI and AGMA all take into account the actual tooth profile and loaded angle $\left(\alpha_{\mathrm{Fen}}\right)$.

- ISO 1996 states that if the root fillet radius is unknown then $\rho_{\mathrm{F} 2}=0.15 \mathrm{~m}_{\mathrm{n}}$. This is a very basic assumption for such a critical parameter.

In summary, this report compares the root bending stress established using ISO 1996, ISO 2006 and VDI with comparison against numerical FEA and experimental strain gauge techniques. The unofficial internal AGMA method was included to highlight its inappropriateness for internal gears.

Where possible, the geometrical values required to calculate the form and geometry factors, such as the root chord length $\left(\mathrm{s}_{\mathrm{Fn}}\right)$ and beam bending height $\left(\mathrm{h}_{\mathrm{Fe}}\right)$ were established directly from accurate $2 \mathrm{D}$ transverse tooth profiles. However, the difficulty associated with physically measuring an ever changing trochoid root fillet radius at a single point, led to this being determined analytically in accordance with the respective standards.

Finally, because ISO 1996 replaces the actual tooth shape with an equivalent "special rack", the geometrical dimensions required for its stress analysis had to be determined analytically in accordance with ISO 6336:1996 method B. Both Kawalek and Wiktor ${ }^{11}$ and von Eiff et al. ${ }^{12}$ present a valuable insight into the errors associated with the assumption of a special rack, as opposed to the actual tooth shape. 


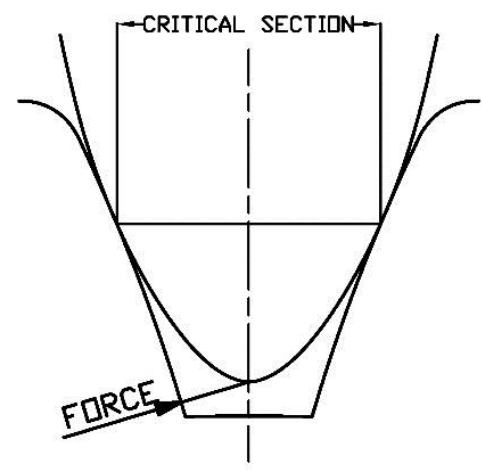

(a)

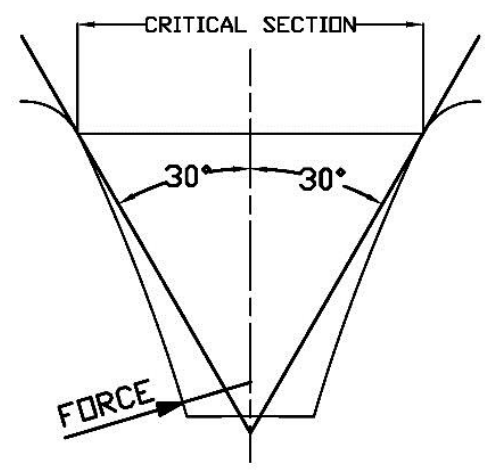

(b)

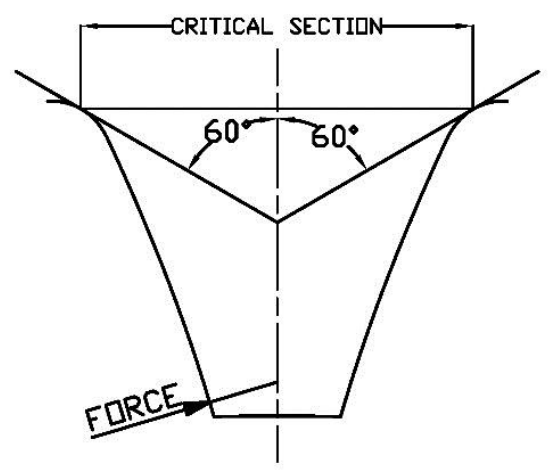

(c)

Figure 1. AGMA and the inscribed Lewis parabola (a), ISO 1996 and the $30^{\circ}$ tangent point (b) and ISO 2006 and VDI and the $60^{\circ}$ tangent point (c)

\section{ISO, VDI, AGMA, FEA and strain gauge comparison}

Due to the difference in the predicted location of maximum root bending stress established in accordance with each of the analytical methods, it was decided to validate the theory against experimentally generated strain gauge results on an actual gear tooth, in addition to FEA. To minimise the errors associated with the positional accuracy of strain gauging normal module gear teeth in locations of high stress gradients, as has been previously discussed ${ }^{18}$, a large module internal gear with a 4 meter reference diameter was manufactured, the details of which are presented in Table 1 and illustrated in Figure 2(a). Note that only partial adjacent gear teeth were manufactured, as has previously been investigated so as not to introduce stress analysis errors ${ }^{18}$. The gear tooth profile was wire cut from hardened (approximately 650Hv) and ground gauge plate with a profile tolerance of $\pm 50 \mu \mathrm{m}$. The gear tooth was statically clamped using a bespoke jig - all faces of which had been precision ground - which was bolted to an Instron loading machine, as illustrated in Figure 2(b). An independent compression load cell, with valid UKAS force certification, was used to calibrate the Instron. A loading anvil with a convex tip was necessary for loading the internal involute profile, and was designed and manufactured such that it was longitudinally stiff but axially (with regards to the gear tooth) flexible. This, together with the accurately ground jig and tooth faces minimised non-uniform load distribution $\left(\mathrm{k}_{\mathrm{F} \beta}\right)$ which was assumed to be unity.

Table 1. The 50mm module internal gear specification

\begin{tabular}{|l|l|l|}
\hline Face width $(\mathrm{mm})$ & $b$ & 10 \\
\hline Normal module $(\mathrm{mm})$ & $m_{n}$ & 50 \\
\hline Pressure angle $(\mathrm{deg})$ & $\alpha_{n}$ & 20 \\
\hline Reference diameter $(\mathrm{mm})$ & $d$ & 4000 \\
\hline Tip diameter $(\mathrm{mm})$ & $d_{a}$ & 3900 \\
\hline Root diameter $(\mathrm{mm})$ & $d_{f}$ & 4125 \\
\hline Base diameter $(\mathrm{mm})$ & $d_{b}$ & 3758.771 \\
\hline Cutter tooth number & $z_{0}$ & 40 \\
\hline Tool tip radius $(\mathrm{mm})$ & $\rho_{f}$ & 19.5 \\
\hline Cutter shift coefficient & $x_{o}$ & 0 \\
\hline
\end{tabular}




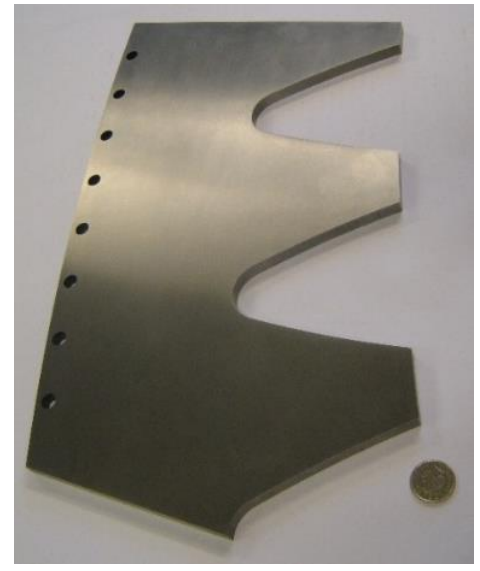

(a)

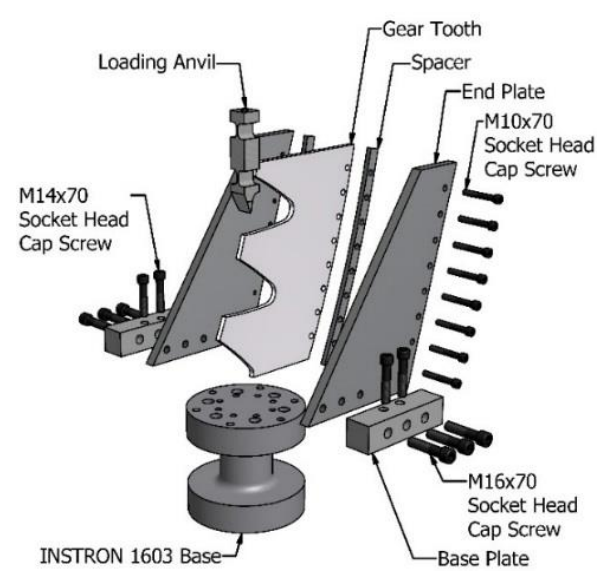

(b)

Figure 2. The 50mm module wire spark eroded internal gear tooth (a) and jig (b)

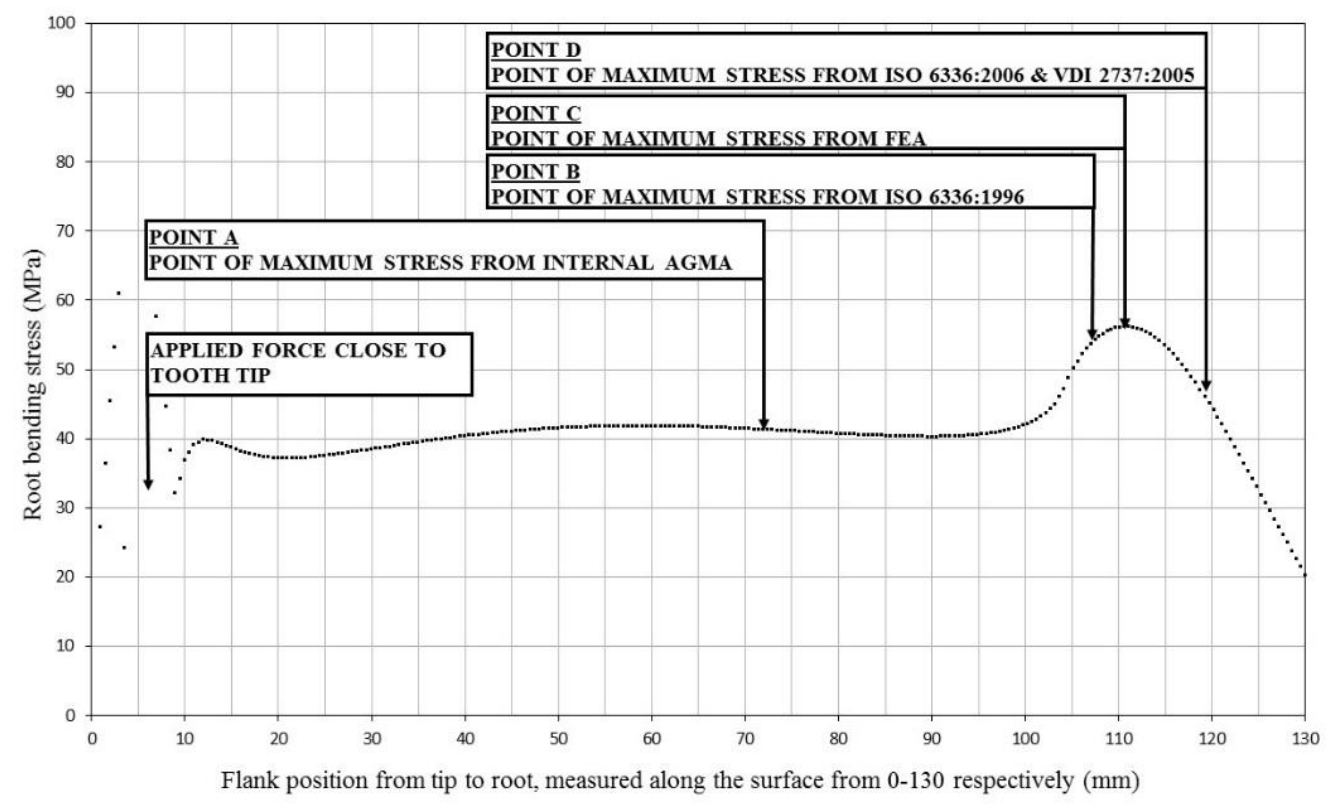

Figure 3. FEA root bending stress profile going from tip to root

As one may expect, FEA of the gear tooth illustrated in Figure 2 merely provided yet another location of maximum root bending stress which was neither at the 30 or 60 degree tangent point - or indeed the tangency of the inscribed parabola - but in fact lay in-between both the $30^{\circ}$ and $60^{\circ}$ degree tangent points as illustrated in Figure 3. This is not unusual as it has already been shown ${ }^{11-12}$ that the angle can vary between approximately 35-60 degrees depending on the gear and tool geometry. The inscribed Lewis parabola (point A) was situated on the flank which is clearly inaccurate. ISO 1996 and the 30 degree tangent point was furthest up the root (Point B) followed by FEA (point C) and ISO 2006 and VDI (point D) i.e. the 60 degree tangent point.

Because of the large variation in the theoretical positions of critical bending, it was decided to experimentally measure stress at each location using $0.79 \mathrm{~mm}$ active width constantan strain gauges, calibrated via a shunt resistor, as illustrated in Figures 4 (a) and (b). To compensate for temperature fluctuations and their resulting errors, three additional unstressed gauges were used, per measurement position, thus 
completing the Wheatstone bridge circuit. With the application of a bridge voltage, an amplified output voltage was supplied via and RPD transducer, which was subsequently converted to stress.

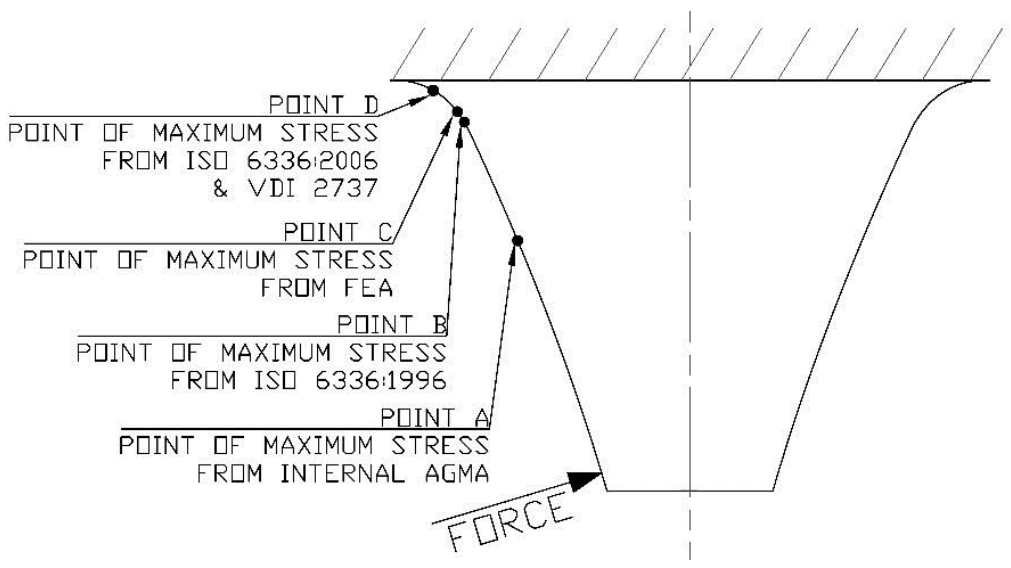

(a)

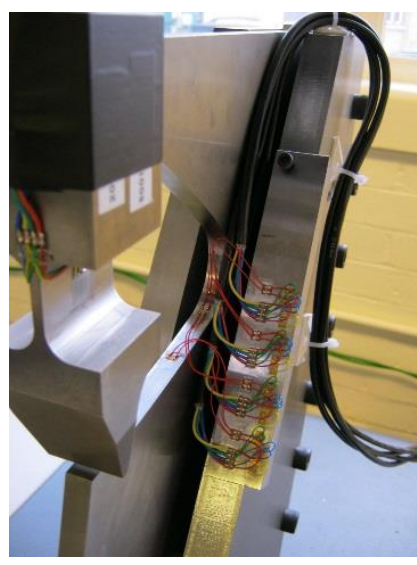

(b)

Figure 4. Locations of maximum bending stress (a) and strain gauged positions (b)

\section{Results}

The analytical stresses established in accordance with ISO, VDI and AGMA, as presented in Eqs. (1) through (3), were compared with numerical stresses based on the ANSYS model illustrated in Figure 5. With regards to the FEA, the bore of the tooth had all degrees of freedom fixed, whilst a line force was applied at the point of loading.

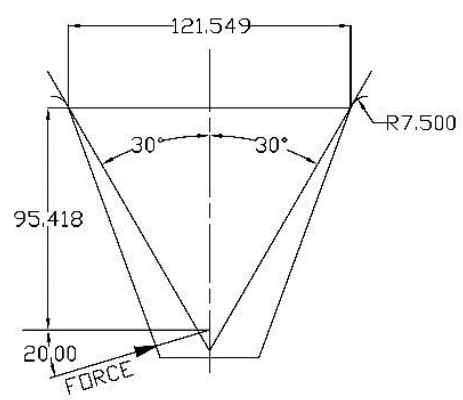

ISO 6336:1996

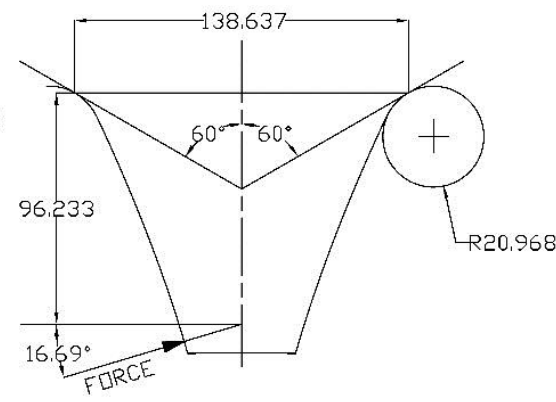

ISO 6336:2006

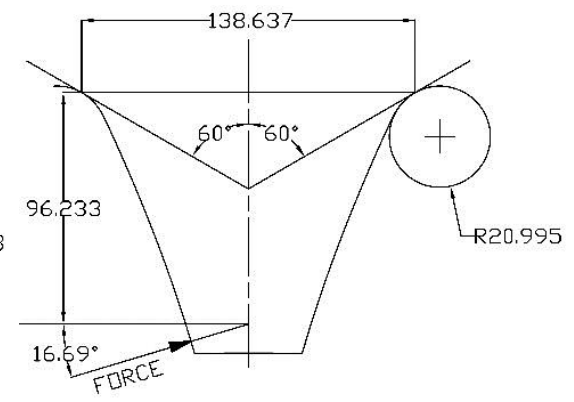

VDI 27372005

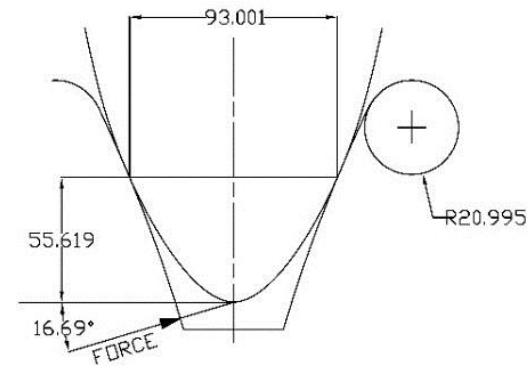

Internal AGMA

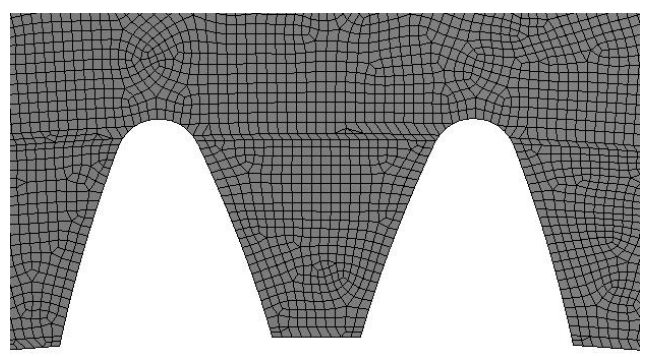

FEA

Figure 5. ISO, VDI, AGMA and FEA stress analysis geometry 
The strain gauge root bending stresses were compared with numerical FEA using a model of the full jig and anvil, as per the experimental set-up illustrated in Figure 6. Note that the fundamental theory of the finite element method is omitted, as this well documented process ${ }^{24}$ is not the intention of this research. However, details of appropriate boundary conditions, mesh descretisation and contact conditions are defined as follows.

Contact conditions between the tip of the convex anvil and concave involute profile were dealt with using the augmented lagrange formulation with frictional flank contact $(\mu=0.125)$ and program controlled normal contact stiffness. Load was applied to the anvil in the vertical direction via its top face, with all degrees on freedom on the base of the jig fixed. The influence of preload from the jig bolts were assumed negligible and were therefore absent from the analysis. All remaining mating jig surfaces were constrained using the ANSYS bonded contact. The difference between the results established using the two different FEA models (Figures 5 and 6) were minimal because the gear tooth, load and point of application were identical, however no single FEA model would accurately represent both scenarios. All FEA gear models were analysed as steel with a Young's modulus of 207GPa in accordance with Callister $^{25}$ and were systematically refined using predominantly 20 node quadratic hexahedral elements until stress had converged to within 1.0\%. Each finite element model was analysed at three different loads of $10 \mathrm{kN}, 15 \mathrm{kN}$ and $20 \mathrm{kN}$, the results of which are illustrated in Figures 7 and 8. The loads were chosen such that suitable levels of bending stress were induced, without causing localised plastic deformation at the anvil to involute interface due to high Hertzian contact stresses. Hence the requirement for a hardened tooth profile as previously discussed.

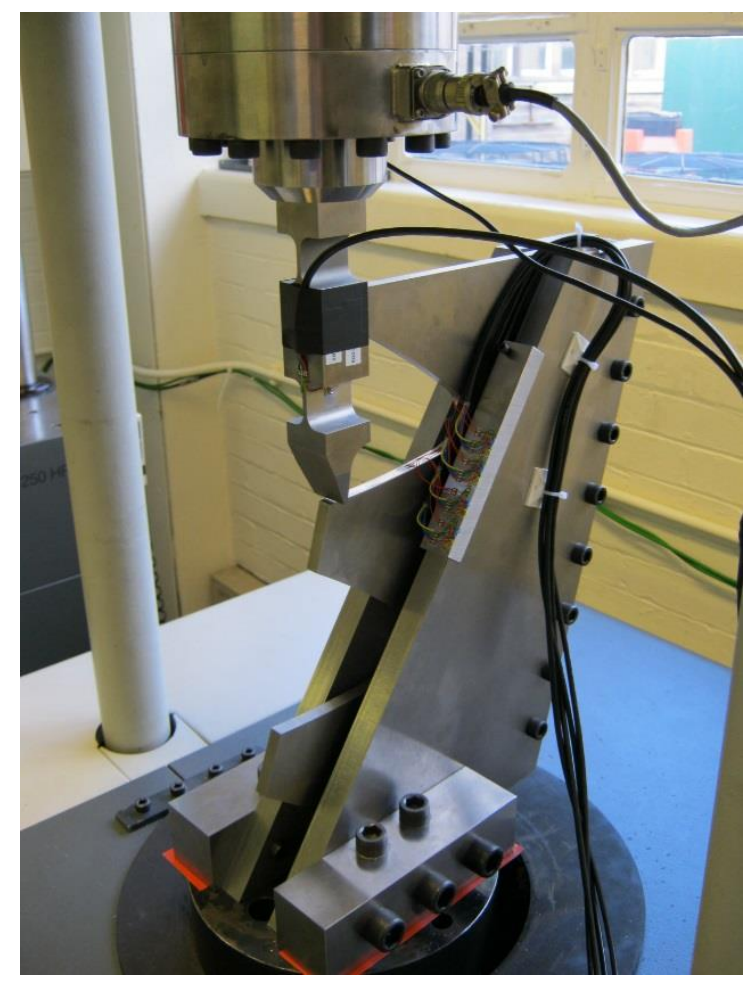

(a)

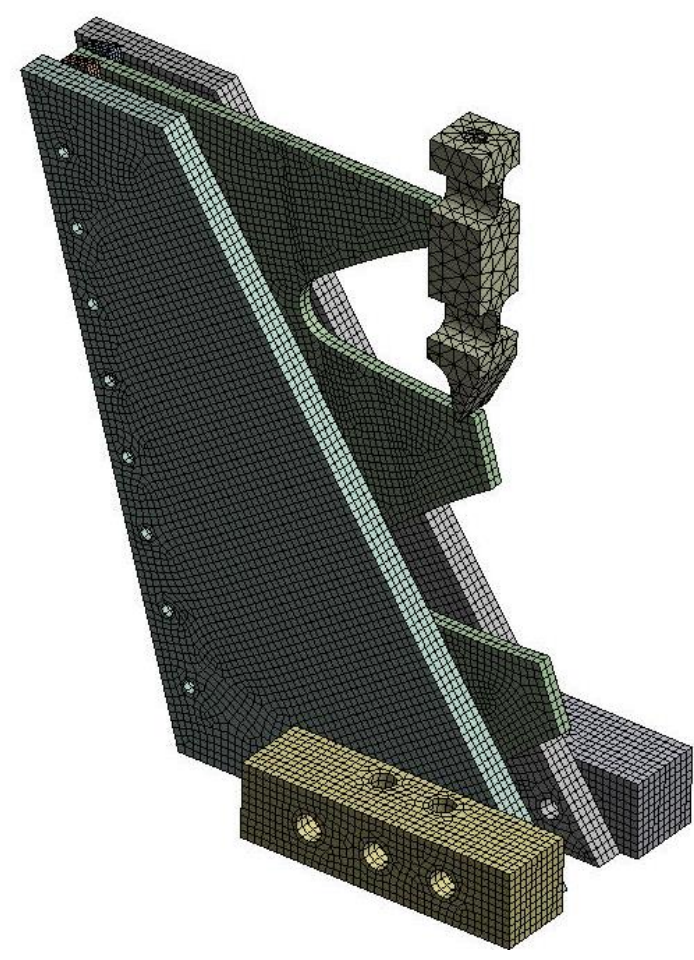

(b)

Figure 6. Experimental (a) and numerical (b) models 


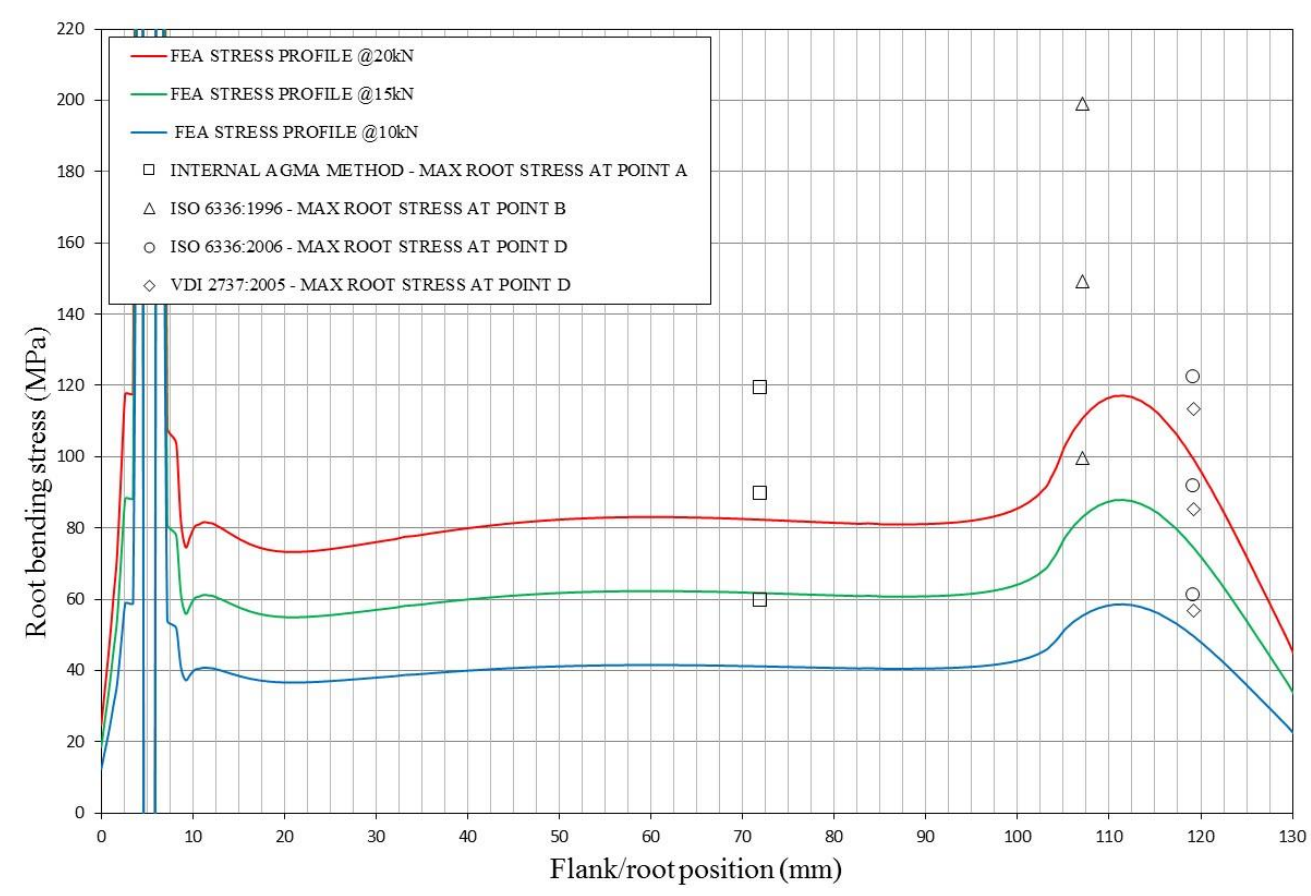

Figure 7. FEA, AGMA, ISO and VDI root bending stress results

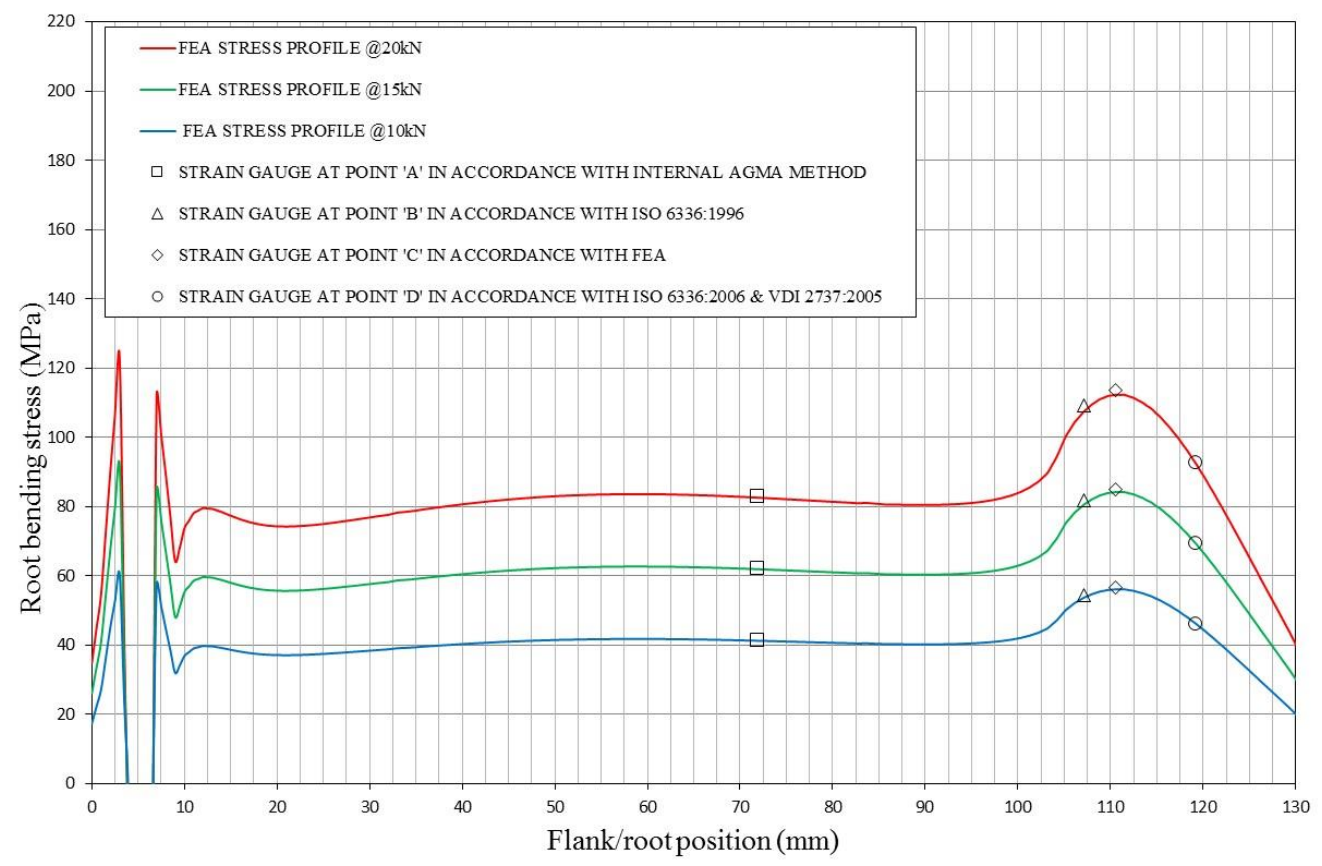

Figure 8. FEA and strain gauge root bending stress results

\section{Discussion and conclusions}

From the results presented in Figure 7 it is clear that there is significant variation in the location and magnitude of maximum root bending stress at each of the respective standards (ISO, VDI and internal AGMA) whilst the results established from the strain gauge experiments illustrated in Figure 8 established that FEA was the most accurate 
method, with an approximate error of only $0.7 \%$. As with any experimental technique such as strain gauging, there exists a degree of measurement uncertainty which was estimated based on the procedures outlined in $^{26}$ to assess the errors associated with 1) strain gauge positional accuracy, 2) UKAS Load cell uncertainty 3) accuracy of the point of loading, 4) measurement resolution error, 5) shunt calibration accuracy and 6) measurement repeatability. This resulted in an average expanded uncertainty (95\% CI) of approximately $1.7 \%$.

Comparing only maximum stress values, ISO 1996 considerably overestimated the root bending stress by $69.8 \%$ because it underestimated the root fillet radius and root chord length as a consequence of assuming a special rack profile and the 30 degree tangent point. VDI was the most accurate official analytical method, underestimating stress by only $3.2 \%$ when compared to FEA, whilst ISO 2006 overestimated stress by $4.3 \%$. Here, the difference between the stresses established in accordance with ISO 2006 and VDI, both of which had almost identical stress concentration factors, was attributed to how the standards deal with the compressive component of stress. It is perhaps understandable that by ignoring the radial component of loading, the tensile fillet stress calculated in accordance with ISO 2006 is overestimated, when compared to the VDI method.

The maximum bending stress established in accordance with the internal AGMA method was within $1.8 \%$ of the FEA results, however this is coincidental because 1) the Lewis parabola makes contact with the flank underestimating the root chord length and beam bending height; thus compensating for one another and masking the true errors of the method and 2) the stress concentration factor based on the work of Dolan and Broghamer ${ }^{3}$ is applied based on root geometry which is completely unassociated with the location of the tangency of the inscribed parabola. Thus, although the internal AGMA method provided the most accurate analytical result, it has no justification, and should not be used, as per AGMA's recommendations.

Although accurate, it can be argued that achieving FEA results requires far more effort than pre-programmed analytical procedures such as ISO 2006 and VDI. It may be argued further that the results established in accordance with both ISO 2006 and VDI are quite reasonable, since other sources of error such as load distribution, manufacturing errors, dynamic loads, application factors, planetary load sharing and permissible material strength - though not strictly an error on stress - probably far exceed the uncertainty surrounding the most current methods of internal gear stress analysis.

\section{Acknowledgements}

This research was conducted by Design Unit at Newcastle University in collaboration with Rolls Royce Plc. With regards to aerospace gears, internal gear stress analysis procedures are of equal significance to their external counterpart and an accurate understanding of the errors associated with each method is of the utmost importance.

\section{Declaration of conflicting interests}

The author(s) declared no potential conflicts of interest with respect to the research, authorship, and/or publication of this article.

\section{Funding}

This work was conducted as part of a $\mathrm{PhD}$ research project, in connection with Rolls Royce Plc, for which the author(s) received no grant funding, for the research, authorship, and/or publication of this article. 


\section{References}

1. Lewis W. Investigation of the strength of gear teeth. In: Proceedings of the Engineers Club of Philadelphia 1892; pp16-23.

2. Timoshenko S and Baud RV, The strength of gear teeth. Mech Eng 1926; 48: 11051109.

3. Dolan TJ and Broghamer EL. A photoelastic study of stresses in gear tooth fillets. In: University of Illinois Engineering Experiment Station Bulletin Series No. 355, 1942.

4. Heywood RB. Tensile fillet stresses in loaded projections. Proc Inst Mech Eng 1948; 159: 384-398.

5. Jacobson MA. Bending stresses in spur gear teeth: proposed new design factors based on a photo-elastic investigation. Proc Inst Mech Eng 1955; 169: 587-609.

6. Kelley BW and Pedersen R. The beam strength of modern gear-tooth design. SAE Tech Paper 1958; 66: 137-157.

7. Allison IM and Hearn EJ. A new look at the bending strength of gear teeth. Exp Mech 1980; 20: 217-225.

8. Andrews JD. A finite element analysis of bending stresses induced in external and internal involute spur gears. J Strain Anal Eng Des 1991; 26: 153-163.

9. Chabert G, Dang Tran T and Mathis R. An evaluation of stresses and deflection of spur gear teeth under strain. ASME J Eng Ind 1974; 96: 85-93.

10. Tsay C-B. Helical gears with involute shaped teeth: geometry, computer simulation, tooth contact analysis, and stress analysis. ASME J Mech Transm Autom Des 1988; 110: $482-491$.

11. Kawalec A and Wiktor J. Tooth-root stress calculation of internal spur gears. Proc Inst Mech Eng, Part B: J. Eng Manuf 2004; 218: 1153-1166.

12. von Eiff $\mathrm{H}$, Hirschmann $\mathrm{KH}$ and Lechner $\mathrm{G}$. Influence of gear tooth geometry on tooth stress of external and internal gears. ASME J Mech Des 1990; 112: 575-583.

13. Kawalec A, Wiktor J and Ceglarek D. Comparative analysis of tooth-root strength using ISO and AGMA standards in spur and helical gears with FEM-based verification. ASME J Mech Des 2006; 128: 1141-1158.

14. Kawalec A and Wiktor J. Simulation of generation and tooth contact analysis of helical gears with crowned flanks. Proc Inst Mech Eng, Part B: J. Eng Manuf 2008; 222: $1147-1160$.

15. Wilcox L and Coleman W. Application of finite elements to the analysis of gear tooth stresses. ASME J Eng Ind 1973; 95: 1139-1148.

16. Sfakiotakis VG, Vaitsis JP and Anifantis NK. Numerical simulation of conjugate spur gear action. Comput Struct 2001; 79: 1153-1160.

17. Atanasovska I, Nikolić-Stanojević V, Dimitrijević D, et al. Finite element model for stress analysis and nonlinear contact analysis of helical gears. Sci Tech Rev 2009; 64: 61-69.

18. Lisle TJ, Shaw BA and Frazer RC. External spur gear root bending stress: A comparison of ISO 6336:2006, AGMA 2101-D04, ANSYS finite element analysis and strain gauge techniques. Mech Mach Theory 2017; 111: 1-9.

19. ISO 6336:1996. Calculation and load capacity of spur and helical gears.

20. ISO 6336:2006. Calculation and load capacity of spur and helical gears.

21. VDI 2737:2005. Calculation of the load capacity of the tooth root in internal toothings with influence of the gear rim.

22. AGMA 908-B89:1989. Geometry factors for determining the pitting resistance and bending strength of spur, helical and herringbone gear teeth. 
23. Savage M, Rubadeux KL and Coe HH. Bending strength model for internal spur gear teeth. 31st Joint Propulsion Conference and Exhibit. San Diego, CA, United States, July 10 th- $12^{\text {th }}, 1995$.

24. NAFEMS. A Finite Element Primer. Glasgow: NAFEMS, 2003.

25. Callister WD. Fundamentals of Material Science and Engineering: An Interactive E-text. 5th ed. USA: John Wiley \& Sons, Inc, 2001.

26. M3003. The Expression of Uncertainty and Confidence in Measurement. 2nd ed. United Kingdom Accreditation Service. 